\title{
We are pleased to introduce you to the first issue of NorDiNa in 2013!
}

Since the last issue was published, we have launched our new Online Journal System:

https://www.journals.uio.no/index.php/nordina/index

All new submission to NorDiNa should now be made through this system. We as editors find the system very promising and believe that this will make the running of the journal even more dynamic in the future. By accessing the same Internet site, all published articles in NorDiNa may also be downloaded. We strongly believe that easy access to the published material is essential for promoting and strengthening science education in the Nordic countries.

As with many electronic systems of this kind, we need some time to discover and solve possible bugs in the system. We therefore apologise in advance if we need to contact authors and referees twice in some instances. However, so far our experience is that the system functions reasonably well.

The running of a scientific journal of high quality is dependent on good access to highly competent and motivated referees. In our new online journal system, you may register as referee, and also describe your specific areas of expertise. This makes it easier for us as editors to allocate the best and most relevant referees to each article submitted to the journal. Some of you have already registered as referees online and we indeed thank you for this. However, we definitely need more people to register. Therefore, please consider to register online as referee in NorDiNa!

In addition to scientific articles, we also want to present abstracts from recent dissertations in NorDiNa, as many of you already know. We as editors follow the publication of new dissertations in the Nordic countries closely. However, we strongly encourage newly graduated $\mathrm{PhDs}$ to initiate using the journal as a channel for spreading their research. The community of Nordic science educators needs to know the issues addressed by our new recruits in the field.

Several articles in this issue of NorDiNa explicitly address inquiry-based learning. Annie-Maj Johansson and Per-Olof Wickman's aim was to elucidate the selective traditions of Swedish primary school teachers in using inquiry-based learning. Four different selective traditions were identified: the fact oriented, the activity oriented, the collaboration oriented and the community oriented traditions. The purpose of Loucas T. Louca and colleagues was to describe the design of a professional development program (PDP) for pre-school teachers in Cyprus, seeking to help them develop teacher responsiveness to children's inquiry. They draw on data from an implementation of this PDP to illustrate how teachers have begun developing their sensitivity towards children's in-class inquiry and building a repertoire of responses. 
Anne Bergliot Øyehaug and Anne Holt's paper reports from a study where a teacher and researchers collaborated on designing science teaching promoting scientific inquiry (processes of science) and science content (product of science) for a group of students (age $11-13$ ). They argue that to succeed in linking science content and processes of science it is important to scaffold student understanding, like providing templates and asking rich and relevant questions.

Some articles in this issue of NorDiNa focus primarily on the learning of science content (or products). The article by Patricia Patrick and colleagues considers the knowledge students (ages 6, 10, and 15 years) have of animals from a cross-cultural perspective. Students from six countries were asked to free-list as many animals as possible and state where they had seen or learned about the animals. Among the findings were that students learn about animals during sociocultural interactions. Anna-Karin Westman's study is an investigation on how students express their understanding of genetic concepts and their relations during peer discussions. Participants in this study were non-major students from a Swedish upper secondary school. The analysis is based on socio-cultural perspectives with focus on how the participants treated the genetic content from the previously presented subject areas in their discussions.

Finally, Anders Szcepanski's reported study describes how 19 teachers linked to preschool and comprehensive school experience the importance of place for learning and teaching in an outdoor educational context. The study shows the experience of teachers using other contexts for learning and teaching than the classroom. Outdoor education is experienced as a place-related toolkit with opportunities to integrate different subjects and anchor teaching in the real world.

We also would like to see more reviews of published books in NorDiNa. In this issue, we present a review of Björn Andersson's book on theories in the science classroom by Birgitte Lund Nielsen. When you have read a new book in the field, may it be interesting and inspiring or mediocre, please consider writing a review to NorDiNa.

Finally, we want to give our warmest thanks to Sonja M. Mork for her great work as editor for NorDiNa, especially with bringing in the online journal system.

Enjoy your read!

Are Turmo

Christina Ottander

Svein Sjøberg 